\title{
TAJDID FIQH MAZHAB SYAFI'I DI MALAYSIA
}

\author{
Oleh: \\ Abdul Karim bin Ali*
}

\begin{abstract}
The madhahib of fiqh had been through of various processes; establishment, strengthening, development, diffusion and reform. As far as Shafi ite madhhab is concerned, it has been through all those processes. The reform and tajdid in the Shafi'ite madhhab can be evaluated in term of its establishment, i.e. proper selection of methods and approaches between two schools of thought; Hijaz and Iraq, between two madhahib of Imam Abu Hanifah and Imam Malik. It also can be seen through his two doctrines; qadim and jadid. As far as Malaysia is concerned, Islam in Malaysia has been spread and taught in accordance to Shafi ite madhhab. It has been strengthened by education system, legal and others. Right now, if there is a difficult and complicated issue, those interested parties have several options, whether to refer to aqwal in Shafi ite madhhab even though it could be weak, or to opt views of other madhhab that could drive the maslahat to the public. In other word, it could lead to the issues of talfiq, taqlid and takhayyur. Therefore, this article attempts to elucidate issues of fiqh in Shafi ite madhhab can grow and solve in Malaysia without to jump to other madhhab. In other word how to develop those issues in the framework of Imam Shafi ite.
\end{abstract}

* Prof. Madya, Jabatan Fiqh \& Usul, Akademi Pengajian Islam, Universiti Malaya, Kuala Lumpur. 


\section{PENDAHULUAN}

Mazhab-mazhab fiqh telah melalui pelbagai proses seperti pembentukan, pemantapan, pengembangan, penyebaran dan juga pembaharuan. Berkait dengan mazhab Syafi'i secara umum, ia juga telah melalui proses-proses tersebut. Secara asasnya, proses tajdid atau pembaharuan oleh mazhab Syafi'i dapat dilihat dari aspek bagaimana ia diasaskan, iaitu antara lainnya pemilihan manhaj pertengahan di antara aliran Hijaz dan aliran Iraq; antara mazhab Abu Hanifah dan mazhab Imam Malik. ${ }^{1}$ Dengan lain perkataan, kewujudan mazhab Syafi'i adalah satu pembaharuan terhadap mazhab dan aliran yang wujud ketika itu. Begitu juga kewujudan qawl qadim dan qawl jadid dalam mazhab Syafi' $\mathrm{i}$ turut menggambarkan berlakunya penilaian semula pandanganpandangan semasa di Iraq yang berasaskan kepada perbezaan tempat, zaman, 'urf dan penemuan sesebuah hadith yang tidak diketahui sebelum ini. ${ }^{2}$

Islam di Malaysia pula dari aspek sejarah telah disebar dan dianuti oleh masyarakatnya melalui pengajaran berdasarkan mazhab Syafi'i. Ia kemudiannya diperkukuhkan lagi melalui sistem pendidikan dan perundangan yang teratur. ${ }^{3}$ Latar belakang tokoh-tokoh agama, tuan-tuan guru, karya-karya yang digunakan dalam pengajaran formal mahupun tidak juga telah menguatkan

1 'Abd al-Ḥamīd Abū Sulaymān (2001), "al-Imām al-Syāfi'i wa Usus Tajdīd Manāhīj al-Tashrī' al-Islāmī”, dalam Salsilah al-Dirāsāt alIslāmiyyah al-Imām al-Syāfi 'ī: Faqīhan wa Mujtahidan. Beirut: Dār al-Taqrīb bayn al-Madhāhibī \& ISESCO.

2 Lihat Siti Khurshiah bt. Mohd Mansor (2001), "Faktor-faktor Perubahan Qawl Qadim kepada Qawl Jadid Imam al-Shafi'i: Hubungannya dengan fiqh Kontemporari”, Disertasi Sarjana Syariah, Jabatan Fiqh \& Usul, Akademi Pengajian Islam, Universiti Malaya; Shihabuddin Muhaemin (2005), “ Pandangan al-Syafi'i Dalam Qawl Qadim dan Qawl Jadid: Satu Analisis”, Disertasi Sarjana Syariah, Jabatan Fiqh \& Usul, Akademi Pengajian Islam, Universiti Malaya.

3 Lihat tulisan-tulisan PM Dr. Abdul Halim el-Muhammady seperti "The Influence of Shafi'ite School in the Muslim Law in Malaysia", ms. 195-197, Seminar Pemikiran Islam (Imam al-Syafi“i) 9-11 Oktober 1989, Pusat Islam Malaysia, Kuala Lumpur. 
lagi kefahaman dan pengamalan umat Islam di Malaysia terhadap mazhab ini di samping pengukuhannya melalui aspek perundangan.

Secara dasarnya, rujukan kepada mazhab Syafi'i dijelaskan dalam enakmen-enakmen negeri. Sebagai contoh, Enakmen Pentadbiran hal Ehwal Agama Islam (Terengganu) 1422/2001M bilangan 2/2001 menyebut:

Seksyen 54 - Qaul muktamad yang hendaklah diikuti.

1. Dalam mengeluarkan apa-apa fatwa di bawah seksyen 50 , atau memperakukan apa-apa pendapat di bawah seksyen 53, Jawatankuasa Fatwa hendaklah pada lazimnya mengikut pendapat-pendapat yang diterima (qaul muktamad) mazhab Syafi'i.

2. Jika Jawatankuasa Fatwa berpendapat bahawa dengan mengikut qaul muktamad mazhab Syafi'i suatu keadaan yang berlawanan dengan kepentingan awam akan terhasil, Jawatankuasa Fatwa bolehlah mengikut qaul muktamad mazhab Hanafi, Maliki atau Hambali.

3. Jika Jawatankuasa Fatwa berpendapat bahawa tiada satu pun qaul muktamad daripada empat mazhab itu boleh diikuti tanpa membawa kepada keadaan yang berlawanan dengan kepentingan awam, Jawatankuasa Fatwa bolehlah membuat fatwa itu mengikut ijtihad tanpa terikat dengan qaul muktamad daripada mana-mana mazhab yang empat itu.

Prosedur yang tercatat dalam enakmen di atas turut terdapat dalam enakmen negeri-negeri lain. Dengan lain perkataan ia adalah seragam. ${ }^{4}$ Justeru itu, fatwa-fatwa hendaklah merujuk qawl mu'tamad dalam mazhab Syafi'i, qawl mu'tamad dalam mazhab Hanafi, Maliki dan Hanbali ataupun tidak terikat dengan mana-mana qawl mu'tamad daripada mana-mana mazhab. Asas perpindahan dalam pemilihan fatwa di atas adalah didasarkan kepada maslahah umum atau kepentingan awam.Berbalik kepada perbendaharan fiqh, apabila sesuatu isu atau persoalan hukum yang agak sukar timbul, kita mempunyai beberapa pilihan sama ada merujuk kepada qawl-qawl dalam mazhab Syafi' $i$ walaupun $d a^{\prime} i \bar{f}$;

Boleh lihat dalam http://www.esyariah.gov.my/ 
atau berpindah kepada pendapat dalam mazhab-mazhab lain yang boleh mendatangkan manfaat (maslahah) kepada orang ramai. Dengan lain perkataan, ia merujuk kepada persoalan talfiq, taqlid dan juga takhayyur. Oleh itu, kertas ini cuba membincangkan sejauhmana persoalan fiqh mazhab Syafi'i boleh berkembang secara sihat di Malaysia tanpa perlu "melompat" kepada pandangan luar mazhab, iaitu dengan mengembangkannya dalam kerangka metodologi yang telah diasaskan oleh Imam al-Syafi'i. Ini kerana, salah satu dapatan awal kajian "Amalan Percampuran Mazhab di Kalangan Masyarakat Islam Malaysia"s menunjukkan bahawa responden secara umumnya berpegang kepada mazhab Syafi'i. Namun, dalam kes-kes yang menimbulkan kesusahan dan kesukaran jika terus berpegang dengan mazhab Syafi'i maka kebanyakan daripada responden bertindak berpindah kepada pendapat lain yang terdapat dalam mazhab-mazhab yang lain.

\section{TAJDID FIQH MAZHAB SYAFI'I}

Tajdid boleh diertikan sebagai pembaharuan (renewal); memulih (islah) atau merangka semula (reshape). Dalam konteks kertas kerja ini tajdid mungkin boleh merujuk kepada usaha merangka semula fiqh Syafi'i di Malaysia sebagai respon kepada pelbagai cabaran, sama ada konflik kaum tua-kaum muda, pendekatan "tidak bermazhab", mempermudahkan urusan agama, Syafi‘i, alSyafi'iyyah dan lain-lain.

Dalam sejarah perkembangan mazhab Syafi'i sendiri, ia telah melalui beberapa proses pembaharuan, tajdid, tanqīh dan tahdhīb. Sebagai contoh, Dr Akram Yūsuf 'Umar al-Qawāsimi menjelaskan dua kali tanqī ${ }^{6}$ telah berlaku dalam mazhab Syafi‘i. Tanqīh

5 Penyelidikan Fundamental UM. Diketuai oleh PM Dr Anisah Ab. Ghani dan dianggotai oleh Dr Raihanah Hj Azahari, PM Dr Noor Naemah Abdul Rahman, PM Dr Abdul Karim Ali, Dr Saadan Man, Dr Luqman Hj Abdullah dan Shahidra Abdul khalil. Mereka merupakan kakitangan akademik Jabatan Fiqh \& Usul, Akademi Pengajian Islam, Universiti Malaya.

6 Tanqị dari segi bahasa bermaksud tahdhib; menyucikan dari bendabenda kotor. Al-Rāzì (1979), Mukhtār al-Ṣiḥ̂̄ăh. Damsyik: al-Maktabah al-Sya'biyyah, h. 675 . 
pertama $(505-676 \mathrm{H})$ diketuai oleh al-Imām al-Rāfi '⿳亠丷厂 (557-623H) dan al-Imām al-Nawawi (631-676H) manakala tanqīh yang kedua (676-1004H) dipimpin oleh Imām Ibn Hajar al-Haytami (m.973H) dan Imām al-Ramli (m.1004H). Tanqīh al-madhhab boleh difahami sebagai menyucikan mazhab dari pendapat-pendapat yang pelik (shädh) dan marjūh atau menerangkan qawl mu'tamad para fuqaha mazhab dalam semua bab fiqh. ${ }^{7}$ Faktor tanqih di atas merujuk kepada beberapa sebab terutamanya "lambakan karya fiqh, takhrïj fiqh yang menyalahi ușūl mazhab, istinbāt yang marjū $h$ atau ijtihad yang shädh taksub mazhab dan sebagainya. ${ }^{8}$

Terdapat seruan agar pengamalan Islam di Alam Melayu ini termasuk Malaysia ditegakkan di atas asas Mazhah Syafi'i dalam bidang fiqh, mazhab Asy'ari dalam aqidah dan pendekatan alGhazāli dalam tasawuf. Kalau diambilkira pandangan ini, maka bagi mempertahan dan mengembangkan kesinambungan serta keutuhan mazhab Syafi"i di Malaysia, proses "tajdid" boleh dilihat dari beberapa pendekatan.

\section{Rujukan Aqwāl dalam Mazhab Syafi'i}

Merujuk kepada aqwāl Imam Syafi‘i atau al-Syāfi'iyyah sahaja dengan tidak melihat kepada pendapat-pendapat yang rājị dalam mazhab-mazhab lain seperti Hanafi, Maliki, Hanbali dan sebagainya. In bererti, sekiranya pendapat atau hukum yang secara tradisinya telah diikuti, tetapi dengan perkembangan semasa, perubahan masa dan tempat ia "dianggap" oleh majoriti masyarakat tidak menepati "mașlahah" atau prinsip keringanan Islam, maka perlu dicari dan dikenalpasti mana-mana qawl yang sesuai dengan keadaan semasa zaman ini walaupun pada asalnya ia adalah qawl yang $d a^{\text {‘ }} \bar{i} f /$ marjūh. Keadaan tersebut boleh berlaku berdasarkan perubahan zaman dan juga tempat.

\section{Rujukan kepada Aqwāl Imām Syafi'i sahaja}

Terdapat juga pandangan bahawa dalam sesetengah kes, masyarakat Islam di Malaysia beramal dengan pandangan ulama

\footnotetext{
$7 \quad$ Akram Yūsuf 'Umar al-Qawāsimì (2003), al-Madkhal ilā Madhhab al-Imām al-Syāfi'ì. Jordan: Dār al-Nafā'is, h. 373.

$8 \quad$ Ibid., hh. 373-374.
} 
al-Syāfi'iyyah, sedangkan ia berbeza daripada pandangan Imam Syafi'i itu sendiri. Justeru itu, perlu diwujudkan suatu usaha untuk mengenal pasti dan membezakan di antara pandangan Imam Syafi'i dan pandangan ulama al-Syāfi'iyyah. Walau bagaimanapun, adakah pandangan-pandangan hukum dalam mazhab Syafi'i perlu dibezakan di antara pendapat Imam Syafi‘ $i$ sendiri berbanding pendapat dan rumusan-rumusan hukum yang telah dihasilkan oleh ulama-ulama dalam mazhab Syafi' ${ }^{\prime}$ ? Dengan lain perkataan, sekiranya kita hanya membatas dan merujuk kepada pendapat Imam Syafi'i sahaja, maka kita terpaksa mengabaikan ijtihad-ijtihad para ulama dalam pelbagai zaman yang telah mengembangkan pendapat Syafi' $i$.

\section{Kerangka Metodologi Mazhab Syafi'i}

Pendekatan ketiga pula merujuk kepada mengaplikasikan kerangka pemikiran dan metodologi pengistibatan hukum oleh Imam Syafi'i itu sendiri. Pendekatan ini (takhrīj al-furü' 'alā al-ușūl) boleh dilakukan terhadap kes-kes lama sebagaimana yang telah dilakukan oleh tokoh ulama mazhab Syafi'i seperti al-Imām alRamli, Ibn Hajar al-Haytamí, al-Nawawi dan sebagainya. Begitu juga, ia boleh dilaksanakan terhadap kes-kes baru.

Dengan lain perkataan, khazanah fiqh mazhab boleh menjadi bahan rujukan, literature review atau asas dalam proses menghasilkan hukum. Justeru para ulama di Malaysia bekerja dalam keadaan tidak terikat dengan fiqhnya (furu'), tetapi berfikir dalam kerangka ijtihad Imam Syafi'i. Oleh itu, mereka perlu betulbetul mahir dalam memahami proses menghasilkan kesimpulan hukum yang dipraktikkan dalam mazhab Syafi' $i$.

Sumber hukum mengikut Imam Syafi'i ialah: al-Quran, alSunnah, Ijma' dan al-Qiyās. Hubung-kait di antara sumber-sumber ini perlu difahami secara mendalam dan menyeluruh. Begitu juga konsep al-bayān yang dihuraikan dengan terperinci oleh alSyafi'i. Di samping itu, asas pemikiran Imam Syafi'i juga perlu diambil-kira seperti ihtiyāt, zāhir al-naș, bahasa Arab, qawāid 
fiqhiyyah, qawā'id ușüliyyah dan lain-lain. ${ }^{9}$ Dr. 'Abd al-Wahhāb Ibrāhim Abū Sulaymān menjelaskan ciri metodologi dalam fiqh Imam Syafi' ${ }^{10}{ }^{10}$ ialah:

i. Istiqrā' Ayat-ayat al-Qur'an

ii. Istiqrā'sunnah Nabi SAW dan àthār Sahabat RA

iii. Berpegang kepada bahasa Arab dalam memahami naș

iv. Aplikasi al-qawā'id al-uṣūliyyah

v. Istidlāl bi al-Ma'qūl wa Maz̧ahirih

vi. Mengaitkan masalah dan hukum dengan qawā'id serta dawābit fiqhìyyah

vii. Metodologi dalam fiqh Muqārin

viii. Adab Khilāf

Sekiranya pendekatan ini digunakan, pandangan-pandangan hukum akan terus berkembang dan bertambah di samping khazanah fiqh yang telah sedia ada. Sebaliknya, jika kita hanya merujuk khazanah fiqh sahaja tanpa keluar dari lingkungan itu, maka pengkayaan khazanah fiqh pasti kurang berlaku. Dalam kerangka pembinaan hukum Islam semasa dan Fiqh Malaysia, pembinaan hukum-hukum baru sepatutnya menggunakan kerangka mazhab Syafi'i dari aspek $u s \underline{u} l$, kaedah, metodologi dan pemikiran dan bukannya hanya bertaqlid kepada fiqh $\left(\right.$ furu $\left.^{\circ}\right)$ sahaja;

\section{HALANGAN DAN KEKANGAN}

Usaha untuk mengekal dan mempertahankan agar Malaysia hanya bermazhab Syafi'i dalam amalan menonjolkan ketaksuban kepada mazhab dan tidak terbuka. Ini kerana rahmat dan keluasan syariat Islam itu tidak hanya dalam pegangan kepada satu-satu mazhab.

$9 \quad$ Lihat Ridzuan bin Ahmad (2006), “ Pemikiran Fiqh Imam al-Syafi'i; Suatu Tinjauan tentang Pemakaiannya dalam Kurikulum Pengajian Syariah di IPTA di Malaysia”, Tesis PhD, USM.

10 'Abd al-Wahhāb Ibrāhīm Abū Sulaymān (1999), Manhajiyyah alImām Muhammad bin Idrīs al-Syāfi'i r.a fî̀ al-Fiqh wa fí Ușūl alFiqh. Beirut: Dār Ibn Haẓm, hh. 39-77. 
Keadaan ini lebih jelas lagi di zaman globalisasi sekarang di mana pendedahan fiqh pelbagai mazhab di dedahkan kepada masyarakat. Justeru ia boleh dianggap sebagai langkah ke belakang.

Dari aspek lain, kebanyakan hukum yang dikeluarkan sekarang merujuk kepada sumber hukum yang pelbagai yang digunakan oleh pelbagai mazhab fiqh seperti mașlahah (maqūsid), istihsān dan sebagainya. Sedangkan secara dasarnya ia tidak dalam senarai pegangan mazhab Syafi'i.

Begitu juga adakah hukum yang diamalkan oleh umat Islam di Malaysia tidak berdasarkan kerangka pemikiran dan metodologi Imam Syafi'i.

\section{PENUTUP}

Persoalan tajdid yang cuba dibincangkan di atas bukanlah bermaksud pembaharuan menyeluruh. Sebaliknya ia cuba membayangkan beberapa cadangan yang boleh dibincangkan lagi atasbeberapakemungkinan.Persoalannya, adakah perlu ditajdidkan fiqh mazhab Syafi'i di Malaysia? Adakah didorong oleh kritikan dan "serangan" yang tidak sehaluan dengan pengamalan mazhab Syafi'i di Malaysia dengan pelabelan bida'ah, menyusahkan atau sebagainya? Atau memang terdapat individu yang merasakan ia perlu ditajdid atas dasar banyak "penyelewengan" yang telah dilakukan oleh mereka yang menganut? Atau telah sampai zamannya ia perlu berubah. 